\title{
Dependence of Solar Radiation Transport in Rice Canopies on Developmental Stage
}

\author{
Atsushi MARUYAMA ${ }^{1 *}$, Tsuneo KUWAGATA ${ }^{2}$, Kazuhiko OHBA ${ }^{1}$ and \\ Taichi MAKI ${ }^{3}$ \\ ${ }^{1}$ National Agricultural Research Center for Kyushu Okinawa Region \\ (Koshi, Kumamoto 861-1192, Japan) \\ ${ }^{2}$ National Institute for Agro-Environmental Sciences (Tsukuba, Ibaraki 305-8604, Japan) \\ ${ }^{3}$ Faculty of Agriculture, Kyushu University (Fukuoka, Fukuoka 812-8581, Japan)
}

\begin{abstract}
Solar radiation in a rice canopy plays an important role in the energy balance on both the plant leaves and soil/water surface. A simple model was derived from the two-stream model to estimate two important factors characterizing radiation in a plant canopy, namely, transmissivity of the canopy $\left(\tau_{\mathrm{c}}\right)$ and the albedo of the canopy (ref), from the absorption coefficient of leaves $(\alpha)$ and leaf inclination factor $(F)$. To clarify the seasonal variation in $\alpha$ and $F$ with growth, season-long observations were conducted in paddy fields during three different cropping seasons. Values of $\alpha$ were almost constant throughout the growing period; however, values of $F$ tended to increase with growth. Values of $F$ were larger than 0.5 (the theoretical value for random leaf distribution) in the late growth stage mainly due to the alterations in leaf geometry with the change in leaf inclination angle along a more horizontal axis after flowering, while in contrast, values of $F$ were less than 0.5 in the early growth stage mainly due to the distribution bias of leaves after transplanting. Seasonal variation in $F$ during different cropping seasons could commonly be expressed as a function of developmental stage (DVS). Using this function, $\tau_{\mathrm{c}}$ and ref could be estimated with more accuracy. The proposed radiation model and function is expected to be applicable in more accurate evaluation of solar radiation, dry matter production and soil/water temperature in paddy fields.
\end{abstract}

Discipline: Agro-meteorology

Additional key words: absorption coefficient, albedo, inclination factor, paddy field

\section{Introduction}

Solar radiation in a plant canopy plays an important role in the energy balance on both the plant leaves and the soil surface, affecting plant growth and production through photosynthesis, leaf temperature and soil/water temperature. The nature of solar radiation in plant canopies has therefore been extensively studied in various disciplines such as agronomy, atmospheric physics and biology $y^{5,712}$, with many models having been developed to describe the absorption, transmittance and reflectance of radiation $^{14,18}$.

Radiation beams penetrating into vegetation are shaded by leaves and attenuate on lower levels of the canopy. This attenuation follows Beer's law ${ }^{12}$ and had been described with an exponential function of the leaf area index (LAI) using the attenuation coefficient $(K)$ in early studies ${ }^{6,15}$. However, a part of the radiation beams shaded by leaves are reflected or transmitted. Therefore, the leaf inclination factor $(F)$ and reflectance/transmittance/absorptance of the leaves rather than $K$ have been used in recent studies ${ }^{14}$ to describe the attenuation of solar radiation with more accuracy. $F$ corresponds to the $K$ of black leaves, and depends on canopy geometry, represented mainly by leaf inclination angle, and leaf shape. Many attempts have been made to determine actual values of $F$ in various plant canopies; e.g. $F=0.97,0.70,0.49$, and 0.29 in sunflower, maize, sorghum, and ryegrass canopies, respectively ${ }^{13}$. Although canopy geometry varies with plant development, variation in $F$ with plant development has not yet been examined, and sometimes causes disagreement in attenuation of solar radiation between the model and field observations ${ }^{2}$. In addition, the variation in $F$ is important for studies in the prediction of crop production, since some models of dry matter production

*Corresponding author: e-mail maruyama@affrc.go.jp

Received 17 March 2006; accepted 19 June 2006. 
are based on the direct proportional relationship with absorbed solar radiation ${ }^{3}$.

Although rice is an important crop worldwide, it is known that the leaf inclination angle of rice varies with development $t^{4}$ and this may cause the variation in $F$. In this study, we tried to clarify and quantify the seasonal variation in the $F$ of rice during the growing season. To this end, a simple radiation model that describes the relationships between $F$ and transmissivity and albedo of the canopy was derived to obtain the $F$ values from the measurements of solar radiation in the canopy. Season-long observations of solar radiation in the rice canopy were conducted in paddy fields at three experimental sites, which have different cropping seasons to clarify the seasonal variation in the $F$ and its difference with cropping type. Further, we determined the common relationship between $F$ and the developmental stage of rice for all cropping seasons to make it possible to use the radiation model with regard to rice development.

\section{Methods}

\section{Derivation of a simple radiation model}

A simple radiation model used in this study was derived from the two-stream radiation model. Primary interactions between two-stream radiation (downward and upward) and vegetation can be expressed using linear differential equations similar to the Kubelka-Munk equation $^{8}$ :

$$
\begin{aligned}
& \frac{d S^{\downarrow}(L)}{d L}=-F(1-\tau) S^{\downarrow}(L)+F r S^{\uparrow}(L) \\
& \frac{d S^{\uparrow}(L)}{d L}=F(1-\tau) S^{\uparrow}(L)-F r S^{\downarrow}(L)
\end{aligned}
$$

where $S^{\downarrow}(L)$ and $S^{\uparrow}(L)$ are the downward and upward solar radiation along a horizontal plane in the canopy at a leaf area depth of $L$ (integrated leaf area from the top of the canopy); $F$ is the leaf inclination factor; and $\tau$ and $r$ are the transmission and reflection coefficient of the leaves, respectively. $F$ is related to the geometry of the leaves, whereby $F=1$ for horizontal leaves, $F=0$ for vertical leaves, and $F=0.5$ for randomly and isotropic directed leaves ${ }^{16}$. Using reasonable assumptions concerning the solution of the above differential equations, the following simple models for transmissivity $\left(\tau_{\mathrm{c}}\right)$ and albedo (ref) can be derived (see Appendix):

$$
\begin{aligned}
& \tau_{\mathrm{c}}=\exp (-\sqrt{\alpha} F L A I) \\
& r e f=r e f_{\max }-\left(r e f_{\max }-r e f_{g}\right) \tau_{c}{ }^{2} \\
& r e f_{\max }=\frac{1-\sqrt{\alpha}}{1+\sqrt{\alpha}}
\end{aligned}
$$

where $\tau_{\mathrm{c}}$ is the transmissivity of the canopy, $\alpha$ is the absorption coefficient of the leaves, $L A I$ is the leaf area index, ref is the albedo of the canopy, $r e f_{\mathrm{g}}$ is the albedo of the ground, and $r e f_{\max }$ is the ultimate albedo value of the canopy when $L A I$ is unlimitedly large.

Eq. (3) corresponds to Beer's law, which has been used in many attempts to determine the $F$ value of various plants. To clarify the seasonal variation, values of $\alpha$ and $F$ were treated as unknown parameters, and calculated using Eqs. (3)-(5) with observed values of $\tau_{\mathrm{c}}, r e f, r e f_{\mathrm{g}}$, and $L A I$ in the following field experiments.

\section{Field experiments}

Experiments were conducted in commercial paddy

\begin{tabular}{|c|c|c|c|c|c|c|c|}
\hline \multirow[t]{2}{*}{ Site } & \multicolumn{3}{|c|}{ Location } & \multicolumn{4}{|c|}{ Cropping period } \\
\hline & Latitude & Longitude & Elevation & Year & Transplanting & Heading & Maturation \\
\hline Saito & $32^{\circ} 06.0^{\prime} \mathrm{N}$ & $131^{\circ} 22.7^{\prime} \mathrm{E}$ & $11 \mathrm{~m}$ & 2002 & March 18 & June 15 & July 25 \\
\hline Saga & $33^{\circ} 12.2^{\prime} \mathrm{N}$ & $130^{\circ} 16.8^{\prime} \mathrm{E}$ & $10 \mathrm{~m}$ & 2002 & June 15 & August 27 & October 8 \\
\hline Aso & $32^{\circ} 56.9^{\prime} \mathrm{N}$ & $131^{\circ} 03.3^{\prime} \mathrm{E}$ & $488 \mathrm{~m}$ & 2003 & May 18 & August 18 & September 25 \\
\hline
\end{tabular}
fields at three different sites to obtain diverse data. Miyazaki Plain (Saito), Chikushi Plain (Saga) and Aso

\begin{tabular}{|c|c|c|c|c|c|c|c|c|}
\hline \multirow[t]{2}{*}{ Site } & \multirow[t]{2}{*}{ Variety } & \multirow[t]{2}{*}{ Plant spacing } & \multirow[t]{2}{*}{ Row direction } & \multicolumn{3}{|c|}{ Fertilization (N: kg/ha) } & \multirow[t]{2}{*}{ Soil type } & \multirow[t]{2}{*}{$r e f_{\mathrm{g}}$} \\
\hline & & & & Basal & Top-dress & Total & & \\
\hline Saito & Koshihikari & $0.16 \mathrm{~m} \times 0.30 \mathrm{~m}$ & North-South & 50 & 30 & 80 & Gray Soil & 0.09 \\
\hline Saga & Koshikikari & $0.16 \mathrm{~m} \times 0.30 \mathrm{~m}$ & East-West & 40 & 30 & 70 & Gray Soil & 0.13 \\
\hline Aso & Koshihikari & $0.16 \mathrm{~m} \times 0.30 \mathrm{~m}$ & East-West & 40 & 40 & 80 & Andosol & 0.08 \\
\hline
\end{tabular}
Basin (Aso) were selected as experimental sites where

Table 1. Location and cropping period in each experimental site

Table 2. Agronomic characteristics of rice cropping and albedo of the ground $\left(r e f_{\mathrm{g}}\right)$ at each experimental site 
representative paddy areas are located in Kyushu, Japan. Rice cropping seasons differed widely at these sites as shown in Table 1. The variety of rice, plant spacing and row direction at each experimental site are shown in Table 2, and recommended agronomic and water management practices were followed at all sites. Although the rice variety was the same (Koshihikari) at all sites, geometric features of the rice plant, such as leaf area, plant length and number of stems, were different at each site depending on the cropping season. For example, $L A I$ of rice at the heading stage was larger at Saga than the other two sites as described later.

Radiation factors were observed from transplanting to maturation of rice in the center of each experimental site. Solar radiation $\left(S^{\downarrow}\right)$ and the reflected solar radiation above the canopy $\left(S^{\uparrow}\right)$ were measured with thermopile pyranometers (Kipp \& Zonen, CM-3), and solar radiation under the canopy $\left(S_{\mathrm{g}}^{\downarrow}\right)$ was measured with a tubular pyranometer (Prede, PCM-200). A tubular pyranometer having $80 \mathrm{~cm}^{2}$ of sensing area to measure the average solar radiation under the canopy was set at $0.12 \mathrm{~m}$ above the soil surface between the rows. There were few leaves in the space below $0.12 \mathrm{~m}$ from the soil surface. Dust, stains and dead leaves on the sensor were removed during routine maintenance at 15-20 day intervals. Measurements were obtained every $5 \mathrm{~s}$ and $10 \mathrm{~min}$ averaged values were recorded using a data logger (Campbell Sci. Inc., CR10X). All measurement values were corrected by calibration, which was conducted before and after the growing season. Daily values of ref and $\tau_{\mathrm{c}}$ were obtained as the ratios of $S^{\uparrow}$ to $S^{\downarrow}$ and $S_{\mathrm{g}}^{\downarrow}$ to $S^{\downarrow}$, respectively. The ref was determined based on the values of ref observed just after transplanting at each experimental site as shown in Table 1. Although the ref $\mathrm{g}$ value could slightly change when the water drained or water became turbid by rainfall, this variation was neglected in the study. LAI was measured at 15-20 day intervals during the rice-growing season using 16 plant samples from 2 plots at each paddy field. A leaf area meter (Li-Cor, LI-3050A) was used to measure leaf area, and yellow leaves that remained on the plant were included in measuring $L A I$. Daily values of $L A I$ were obtained using the measurement values based on the smoothing spline method ${ }^{17}$.

\section{Results and discussion}

LAI moderately increased after transplanting, reached a maximum around the heading stage, and decreased thereafter. The $\tau_{\mathrm{c}}$ decreased with increasing LAI until heading at all sites as shown in Fig. 1. The $\tau_{\mathrm{c}}$ of Saga did not decrease just after transplanting when $L A I$ increased. This could be due to the sensor placement of the tubular pyranometer $(0.12 \mathrm{~m}$ above the soil surface) since rice plants were small. However, $\tau_{\mathrm{c}}$ of Saito and Aso decreased from the beginning, and this could be related to the difference in solar elevation at transplanting time (it was highest at Saga). After heading, LAI decreased but the $\tau_{\mathrm{c}}$ was lower than that before heading at the same $L A I$ level. This indicates that the parameter $\sqrt{\alpha} F$ in Eq. (3) is not constant, which corresponds to the apparent attenuation coefficient. Seasonal variation in $\sqrt{\alpha} F$ is shown in Fig. 2. $F$ values showed large variation, increasing from 0.2 to 0.6 during the growing season. To clarify the parameter affecting the variation in $\sqrt{\alpha} F$, seasonal variation in $\alpha$ and $F$ are also shown in the figure (the latter half of the data for Aso was missed because of instrumental trouble).

The $\alpha$ at each experimental site remained constant throughout the growing period. Average values of $\alpha$ were 0.46 at Saito, 0.34 at Saga, and 0.43 at Aso, respectively. The $\alpha$ of Saga was lower than that of the other two sites although the rice variety was the same. Based on Eq. (2), the smaller $\alpha$ value at Saga is attributed to the ref $f_{\max }$ value ( 0.26 at Saga on average) that is larger than at the other two sites (0.19 at Saito, and 0.21 at Aso on average). The reason for the smaller $\alpha$ value at Saga might be related to a difference in leaf thickness or leaf color (chlorophyll concentration), since the LAI of Saga was larger than that of the other two sites during the growing season under similar fertilizer condition. However, it is difficult to explain the almost constant values of $\alpha$ during the season, because the leaf color of rice changed with the growth stage. Other unexpected reasons may include the effect of solar elevation, the ratio of the direct solar

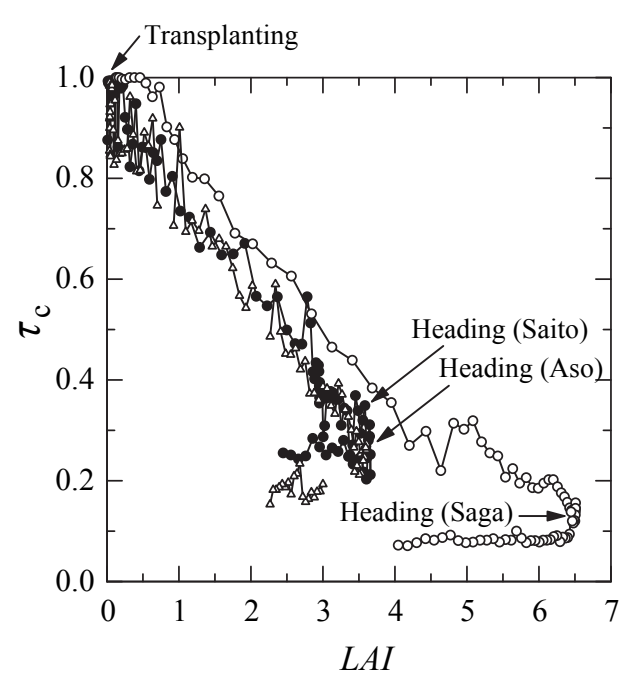

Fig. 1. Relationship between leaf area index $(L A I)$ and transmissivity $\left(\tau_{\mathrm{c}}\right)$ in the rice canopy at each experimental site

Arrows indicate the transplanting and heading time. $\rightarrow-$ Saito, -૦-: Saga, $\triangle-$ : Aso. 

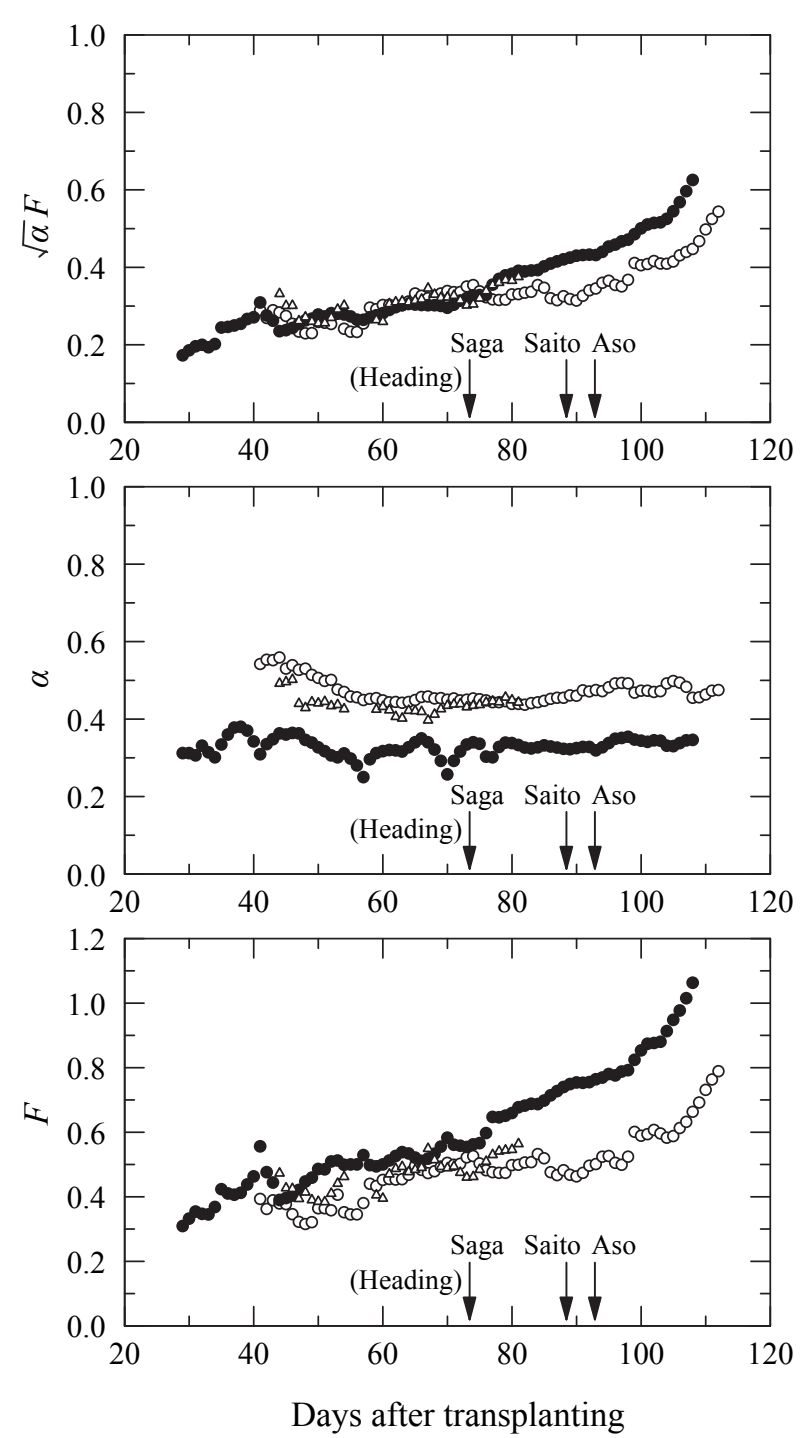

Fig. 2. Seasonal variation in the apparent attenuation coefficient $(\sqrt{\alpha} F)$, the absorption coefficient of the leaves $(\alpha)$ and the leaf inclination factor $(F)$ in the rice canopies at each experimental site

Arrows indicate the heading time.

$\circ:$ Saito, •: Saga, $\Delta:$ Aso.

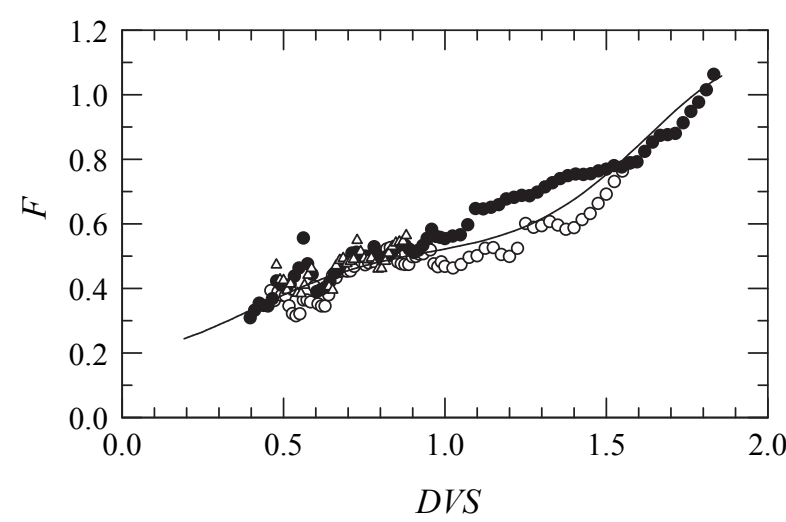

Fig. 3. Dependence of leaf inclination factor $(F)$ on the developmental stage of rice $(D V S)$

$\circ:$ Saito, $\bullet$ : Saga, $\Delta:$ Aso, $-: F=f(D V S)$. radiation, and albedo of the soil, which were neglected in the model. For example, a lower solar elevation in late season of Saga might cause a lower albedo on the canopy (or higher reflection on leaf and water surface by specular reflection in some situations). Another example, albedo of the soil might affect the albedo on the canopy during the water-drained period. However, similar changes in solar elevation and water management also occurred at the other two sites and the $\alpha$ of Saga was smaller through the season; so that it is difficult to specify a reason only from the observed data. It is necessary on further study to examine or directly measure the $\alpha$ of rice at various places and growth stages. In any case, approximate values of $r e f_{\max }$ for rice canopies ranged from 0.17 to 0.27 in previous studies ${ }^{6,10,15}$, suggesting that the results of the present study were within the usual range.

On the other hand, $F$ values showed a large seasonal variation so that the change in $\sqrt{\alpha} F$ was mainly caused by the variation in $F$. Values of $F$ had an increasing trend from 0.5 to 1.0 in the late growing period. This could be due to alterations in leaf geometry with the change in leaf inclination angle along a more horizontal axis after heading. Further, $F$ remained less than 0.5 (the theoretical value for random leaf distribution) in the early growing period. This could be due to the distribution bias of leaves (almost all leaves are located near stems) commonly observed in rice in the early growing period ${ }^{9}$. As other reasons, the change in solar elevation or the ratio of the direct solar radiation could also slightly affect the $F$ values. The increase in $F$ with time differed between sites due to the different heading times. To generalize the growth stages of rice at each experimental site, the concept of developmental stage ${ }^{1}(D V S)$ rather than actual days after transplanting was used. In this study, $D V S$ was defined as $D V S=0$ at transplanting, $D V S=1$ at heading, and $D V S=2$ at maturation. Values were calculated as $D V S$ $=$ days after transplanting $(D A T) /$ days from transplanting to heading $\left(D A T_{\mathrm{h}}\right)$ for $0<D V S<1$, and $D V S=$ days after heading $(D A H) /$ days from heading to maturation $\left(D A H_{\mathrm{m}}\right)$ for $1<D V S<2$. Fig. 3 shows the dependence of $F$ on $D V S$. The timing of the increase in $F$ based on $D V S$ was almost the same at all experimental sites, and the relationship between $F$ and DVS could be expressed using:

$$
\begin{aligned}
F=F_{1} & +\left(F_{0}-F_{1}\right) \exp \left\{-\left(\theta_{1} D V S\right)^{2}\right\} \\
& +\left(F_{2}-F_{1}\right) \exp \left[-\left\{\theta_{2}(D V S-2)\right\}^{2}\right]
\end{aligned}
$$

where $F_{0}, F_{1}$ and $F_{2}$ are the values of $F$ at transplanting $(D V S=0)$, heading $(D V S=1)$ and maturation $(D V S=$ $2)$, respectively; and $\theta_{1}$ and $\theta_{2}$ are parameters affecting the timing of increase after transplanting and heading, respectively. The following values were obtained using 
the least-squares method: $F_{0}=0.21, F_{1}=0.52, F_{2}=1.10$, $\theta_{1}=1.78$, and $\theta_{2}=1.91$. Seasonal variation in $F$ at individual developmental stages could subsequently be calculated using this equation. Here, it is expected that the transport of solar radiation in each developmental stage of rice affected not only leaves but also stems and panicles. Therefore, plant area index (PAI), which is the sum of the foliage (leaves, stems and panicles) projected area, is sometimes used in similar studies instead of $L A I$. We additionally determined the relationship between $D V S$ and the value of $F$ calculated based on $P A I$ rather than $L A I$ in Eq. (3). The relationship could be expressed using the same equation (Eq. (6)), and the following parameter values were obtained in a similar way: $F_{0}=0.21, F_{1}=$ $0.41, F_{2}=0.70, \theta_{1}=1.94$, and $\theta_{2}=2.06$. These results can therefore be applied to radiation transport models based on PAI.

Using Eqs. (3)-(5) and (6), the two important factors characterizing radiation in the canopy $\left(\tau_{\mathrm{c}}\right.$ and $\left.r e f\right)$ can be calculated in response to the variation in $F$. Comparison of calculated and observed values of $\tau_{\mathrm{c}}$ and $r e f$ are shown in Figs. 4 and 5, respectively. Here, calculated values in the case when considering the variation in $F$ ( $F$ was calculated as $F=f(D V S)$ using Eq. (6)) and when neglecting the variation in $F$ ( $F$ was fixed at $F=0.5$ as the theoretical value for random leaf distribution) are shown in the figure. In both cases, $\alpha$ was fixed at $\alpha=0.46$ for Saito, $\alpha=0.34$ for Saga, and $\alpha=0.43$ for Aso, respectively. Calculated values for the ref of both cases showed good agreement with observed values at all sites and there was no significant difference between the two cases. However, calculated values of $\tau_{\mathrm{c}}$ had a better agreement with the case when $F=f(D V S)$ than the case when $F=0.5$ at all sites especially during the late stage of rice growth. The root mean square errors (RMSE) of calculated values when $F$ $=0.5$ and when $F=f(D V S)$ for all data were $9.6 \%$ and $6.5 \%$ for the $\tau_{\mathrm{c}}$ estimation, and $1.7 \%$ and $1.5 \%$ for the ref estimation, respectively. For estimating the transmittance of solar radiation in a rice canopy, it is more useful from the viewpoint of accuracy to consider the variation in $F$ with development.
The difference in calculated results when considering and neglecting the variation in $F$ is also important for studies in prediction of rice production, since the $\tau_{\mathrm{c}}$ and ref values affect the absorbed solar radiation $\left(S_{\mathrm{c}}\right)$, and many crop production models are based on the direct proportional relationship between $S_{\mathrm{c}}$ and dry matter production ${ }^{3}$. To evaluate the effect of variation in $F$, absorbed solar radiation in the canopy at each experimental site was calculated in both cases $(F=0.5$ and $F=f(D V S))$ as follows:

$$
S_{\mathrm{c}}=(1-r e f) S^{\downarrow}-\left(1-r e f_{\mathrm{g}}\right) \tau_{\mathrm{c}} S^{\downarrow}
$$

Table 3 shows comparisons of accumulated values of $S_{\mathrm{c}}$ in both cases during rice growing periods. Accumulated $S_{\mathrm{c}}$ from transplanting to heading in the case when $F=f(D V S)$ was $6-8 \%$ smaller than the case when $F=0.5$, because of the higher $\tau_{\mathrm{c}}$ value that is shown in Fig. 4 . On the other hand, accumulated $S_{\mathrm{c}}$ from heading to maturation was $17-28 \%$ larger in the case when $F=f(D V S)$ than in the case when $F=0.5$, because of the lower $\tau_{\mathrm{c}}$ value. A 17$28 \%$ difference in accumulated $S_{\mathrm{c}}$ after heading largely affects the prediction of the dry matter production after heading. The production in the leaf after heading plays an important role as a source of carbohydrate for grain filling especially under high temperature condition $\mathrm{s}^{11}$, therefore it is useful in these studies to consider the variation in $F$ after heading.

\section{Conclusions}

A simple model allowing estimation of two important factors characterizing radiation in a plant canopy $\left(\tau_{\mathrm{c}}\right.$ and $r e f$ ) with the values of $\alpha$ and $F$ was derived from the two-stream radiation model. To clarify the seasonal variation in $F$ with rice growth, season-long observations were conducted in paddy fields during different cropping seasons. Values of $F$ tended to increase with rice growth, remaining larger than 0.5 (theoretical value for random and isotropic leaf distribution) in the late stage of growth mainly because of alterations in leaf geometry with the

Table 3. Comparison of accumulated values of absorbed solar radiation $\left(S_{\text {f }}\right)$ estimated using the model in the case when $F$ was fixed $(F=0.5)$ and when $F$ was calculated from developmental stage $(F=f(D V S))$, and the ratios of both calculated values at each experimental site

\begin{tabular}{|c|c|c|c|c|c|c|c|c|c|}
\hline \multirow[t]{3}{*}{ Site } & \multicolumn{3}{|c|}{ Transplanting to heading } & \multicolumn{3}{|c|}{ Heading to maturation } & \multicolumn{3}{|c|}{ Total } \\
\hline & \multicolumn{3}{|c|}{ Accumulated $S_{\mathrm{c}}(\mathrm{MJ})$} & \multicolumn{3}{|c|}{ Accumulated $S_{\mathrm{c}}(\mathrm{MJ})$} & \multicolumn{3}{|c|}{ Accumulated $S_{c}(\mathrm{MJ})$} \\
\hline & $F=0.5$ & $F=f(D V S)$ & Ratio & $F=0.5$ & $F=f(D V S)$ & Ratio & $F=0.5$ & $F=f(D V S)$ & Ratio \\
\hline Saito & 439 & 413 & 0.94 & 312 & 399 & 1.28 & 750 & 813 & 1.08 \\
\hline Saga & 457 & 420 & 0.92 & 360 & 422 & 1.17 & 816 & 843 & 1.03 \\
\hline Aso & 330 & 308 & 0.93 & 297 & 368 & 1.24 & 627 & 676 & 1.08 \\
\hline
\end{tabular}



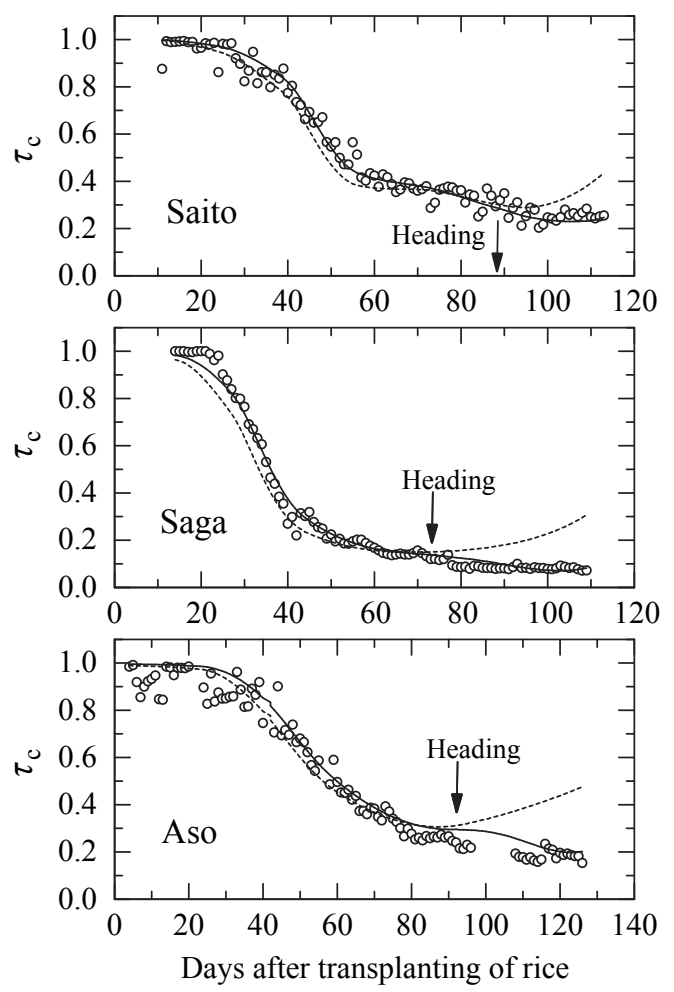

Fig. 4. Comparisons between the observed and calculated values of transmissivity $\left(\tau_{c}\right)$

Arrows indicate the heading time at each experimental site.

○: Observed, ---- : Calculated $(F=0.5)$,

- Calculated $(F=f(D V S))$.

change in leaf inclination angle along a more horizontal axis after heading, and less than 0.5 in the early stage of growth mainly because of the distribution bias of leaves after transplanting. These seasonal variations in $F$ during different cropping seasons can be commonly expressed as a function of DVS. Using this function, $\tau_{\mathrm{c}}$ and ref could be estimated using the simple radiation model with more accuracy.

Similar changes in $F$ caused by the change in leaf inclination angle with development have been suggested with other crops such as wheat and barley. Therefore, modeling of $F$ in other plant canopies is also expected to be possible with the proposed equation. Further, since the variation in the $F$ value affected the absorbed solar radiation, the model is also expected to be applicable for studies in prediction of crop production.

\section{Appendix}

\section{Solutions of differential Eqs. (1) and (2)}

Derivation of simple radiation model Eqs. (3)-(5) from the Kubelka-Munk equation was reported in previ-
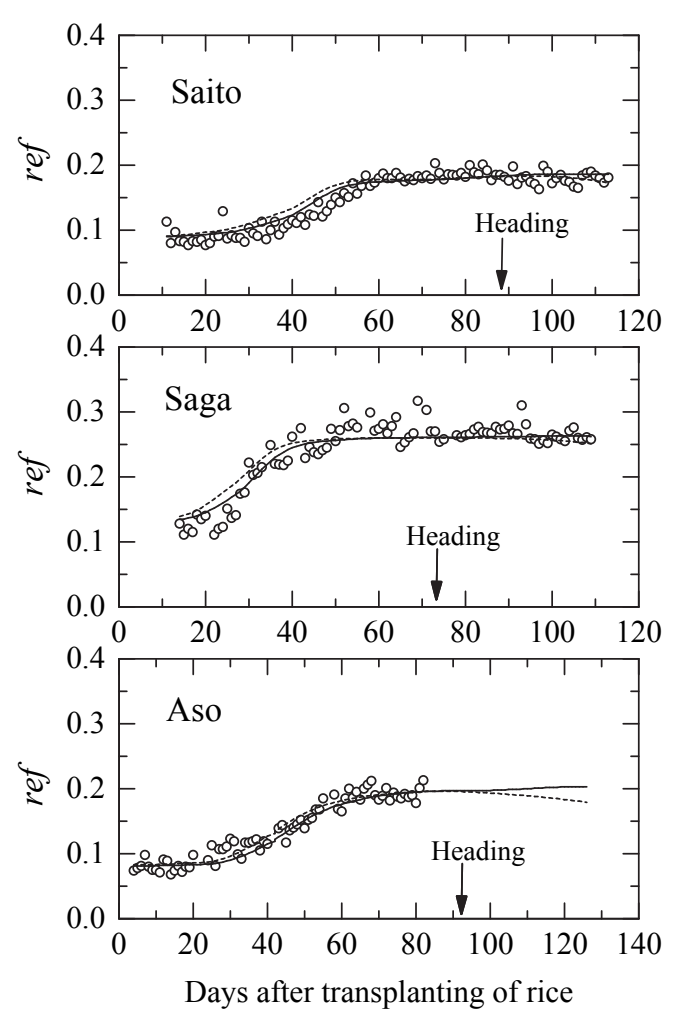

Fig. 5. Comparisons between the observed and calculated values of albedo (ref)

Arrows indicate the heading time at each experimental site.

०: Observed, ----- : Calculated $(F=0.5)$,

- Calculated $(F=f(D V S))$.

ous studies ${ }^{2}$, but the derivation from the two-stream radiation model Eqs. (1) and (2) was not reported. It can be derived as follows.

Linear differential equations have general solutions. Eqs. (1) and (2) can be solved using an eigenvalue $(\lambda)$ and component of the eigenvector $\left(r e f_{\max }\right)$ as follows:

$$
\begin{aligned}
& S^{\downarrow}(L)=C_{1} e^{\lambda L} \times r e f_{\text {max }}+C_{2} e^{-\lambda L} \\
& S^{\uparrow}(L)=C_{1} e^{\lambda L}+C_{2} e^{-\lambda L} \times r e f_{\text {max }} \\
& \lambda=F \sqrt{(1-\tau)^{2}-r^{2}} \\
& r e f_{\text {max }}=\frac{(1-\tau)-\sqrt{(1-\tau)^{2}-r^{2}}}{r}
\end{aligned}
$$

where $C_{1}$ and $C_{2}$ are integration constants. Substituting the boundary conditions of $S^{\downarrow}(0)=S^{\downarrow}$ and $S^{\uparrow}(L A I)=r e f_{\mathrm{g}}$ $S^{\downarrow}$ (LAI) (where, $S^{\downarrow}$ is global solar radiation; ref $f_{\mathrm{g}}$ is the albedo of the ground) into Eqs. (A1) and (A2), values of both constants are obtained as follows: 


$$
\begin{aligned}
& C_{1}=\frac{C_{3} e^{-2 \lambda L A I}}{1+r e f_{\text {max }} C_{3} e^{-2 \lambda L A I}} S^{\downarrow} \\
& C_{2}=\frac{1}{1+r e f_{\text {max }} C_{3} e^{-2 \lambda L A I}} S^{\downarrow} \\
& C_{3}=-\frac{\left(r e f_{\text {max }}-r e f_{\mathrm{g}}\right)}{\left(1-r e f_{\text {max }} r e f_{\mathrm{g}}\right)}
\end{aligned}
$$

Using Eqs. (A1)-(A7), downward and upward solar radiation at a given leaf area depth (given height), $S^{\downarrow}(L)$ and $S^{\uparrow}$ $(L)$, respectively, can be calculated from the values of $F$, $\tau, r$, and $r e f_{\mathrm{g}}$.

Transmissivity of the canopy $\left(\tau_{c}\right)$ and albedo of the canopy (ref) are derived from:

$$
\begin{aligned}
& \tau_{\mathrm{c}}=\frac{S^{\downarrow}(L A I)}{S^{\downarrow}(0)}=\frac{\left\{\left(1-r e f_{\max }^{2}\right) /\left(1-r e f_{\max } r e f_{\mathrm{g}}\right)\right\} e^{-\lambda L A I}}{1+r e f_{\max } C_{3} e^{-2 \lambda L A I}} \\
& r e f=\frac{S^{\uparrow}(0)}{S^{\downarrow}(0)}=\frac{r e f_{\max }+C_{3} e^{-2 \lambda L A I}}{1+r e f_{\max } C_{3} e^{-2 \lambda L A I}}
\end{aligned}
$$

where the component of the eigenvector, $r e f_{\max }$, corresponds to the ultimate albedo value of the canopy when $L A I$ is unlimitedly large, since ref is equal to $r e f_{\max }$ when $L A I=\infty$ in Eq. (A9).

Neglecting the second order terms $r e f_{\max }{ }^{2}$ and $r e f_{\max } r e f_{\mathrm{g}}$, since they are sufficiently small ${ }^{13}$, Eqs. (A1) and (A2) are expressed as:

$$
\begin{aligned}
& S^{\downarrow}(L)=e^{-\lambda L} S^{\downarrow} \\
& S^{\uparrow}(L)=\left\{r e f_{\text {max }}-\left(r e f_{\text {max }}-r e f_{\mathrm{g}}\right) e^{2 \lambda(L-L A I)}\right\} \times e^{-\lambda L} S^{\downarrow}
\end{aligned}
$$

Similarly, (A8) and (A9) are expressed as:

$$
\begin{aligned}
& \tau_{\mathrm{c}}=e^{-\lambda L A I} \\
& r e f=r e f_{\text {max }}-\left(r e f_{\text {max }}-r e f_{\mathrm{g}}\right) e^{-2 \lambda L A I}
\end{aligned}
$$

Further, by approximating $\tau=r=(1-\alpha) / 2$, as observed with various plant leaves ${ }^{13}$, Eqs. (A3) and (A4) are expressed as:

$$
\begin{aligned}
& \lambda=F \sqrt{\alpha} \\
& r e f_{\max }=\frac{1-\sqrt{\alpha}}{1+\sqrt{\alpha}}
\end{aligned}
$$

Equations (A12), (A13), (A14), and (A15) then give the simple radiation model Eqs. (3)-(5).

\section{References}

1. De Wit, C. T. (1970) Dynamic concepts in biology. In Prediction and measurement of photosynthetic productivity, ed. Setlik, I., PUDOC, Wageningen, 17-23.

2. Goudriaan, J. (1977) Crop micrometeorology: a simulation study. PUDOC, Wageningen, pp. 249.

3. Horie, T. (1987) A model for evaluating climatic productivity and water balance of irrigated rice and its application to Southeast Asia. Southeast Asian Stud., 25, 62-74.

4. Ito, A. (1969) Geometrical structure of rice canopy and penetration of direct solar radiation. Jpn. J. Crop Sci., 38, 355-363 [In Japanese with English summary].

5. Kawakata, T. (2005) Application of two-stream model to solar radiation of rice canopy. J. Agric. Meteorol., 61, 123-129 [In Japanese with English summary].

6. Kishida, Y. (1973) Agro-metrological studies on utilization of radiant energy under cultivated field conditions (1). Bull. Kyushu Agric. Exp. Stn., 17, 1-79 [In Japanese with English summary].

7. Kondo, J. \& Watanabe, T. (1992) Studies on the bulk transfer coefficients over a vegetated surface with a multiplayer energy budget model. J. Atmos. Sci., 49, 21832199.

8. Kubelka, P. \& Munk, F. (1931) Ein beitrag zur optic der farbanstriche. Zeitschr. Techn. Physik, 11, 593-601.

9. Maruyama, A., Kuwagata, T. \& Ohba, K. (2005) Measurement error of plant area index using plant canopy analyzer and its dependence on mean tilt angle of the foliage. $J$. Agric. Meteorol., 61, 229-233 [In Japanese with English summary].

10. Maruyama, A., Ohba, K. \& Kurose, Y. (1998) Estimating the water temperature of paddy fields under abnormal weather conditions using an equilibrium water temperature model. J. Agric. Meteorol., 54, 247-254 [In Japanese with English summary].

11. Matsushima, S. (1957) Analysis of developmental factors determining yield and yield prediction in lowland rice. Bull. Nat. Inst. Agric. Sci., A5, 1-270 [In Japanese with English summary].

12. Monsi, M. \& Saeki, T. (1953) Über den lichtfaktor in den pflanzengesellschaften und seine bedeutung für die stoffproduktion. Jpn. J. Bot., 14, 22-52.

13. Monteith, J. L. \& Unsworth, M. H. (1990) Principles of environmental physics, 2nd ed. Edward Arnold, London, pp. 291.

14. Myneni, R. B., Ross, J. \& Asrar, G. (1989) A review on the theory of photon transport in leaf canopies. Agric. For. Meteorol., 45, 1-153.

15. Research Group of Evapotranspiration (1967) Radiation balance of paddy field. J. Agric. Meteorol., 22, 97-102 [In Japanese with English summary].

16. Ross, J. (1975) Radiative transfer in plant communities. In Vegetation and the atmosphere, vol. 1: principles, ed. Monteith, J. L., Academic Press, London, 13-55.

17. Simonoff, J. S. (1998) Smoothing methods in statistics, 2nd ed. Springer, Tokyo, pp. 338.

18. Watanabe, T. \& Ohtani, Y. (1995) A simple model of shortwave-radiation transport within canopy. J. Agric. Meteorol., 51, 57-60 [In Japanese]. 